\title{
Self-assembly of dermal papilla cells into inductive spheroidal microtissues on poly(ethylene-co-vinyl alcohol) membranes for hair follicle regeneration
}

\author{
Tai-Horng Young ${ }^{\mathrm{a}}$, Chiao-Yun Lee ${ }^{\mathrm{a}}$, Hsien-Ching Chiu ${ }^{\mathrm{b}}$, Chih-Jung Hsu ${ }^{\mathrm{b}}$, Sung-Jan Lin ${ }^{\mathrm{a}, \mathrm{b}, *}$ \\ a Institute of Biomedical Engineering, College of Medicine and College of Engineering, National Taiwan University, No. 1, Sec. 1, Jen-Ai Road, Taipei 100, Taiwan \\ ${ }^{\mathrm{b}}$ Department of Dermatology, National Taiwan University Hospital and National Taiwan University College of Medicine, Taipei, Taiwan
}

\section{A R T I C L E I N F O}

Article history:

Received 19 April 2008

Accepted 12 May 2008

Available online 3 June 2008

\section{Keywords:}

Aggregation

Dermal papilla

Spheroid

Tissue engineering

Adhesivity

Biomaterial

\begin{abstract}
A B S T R A C T
Self-aggregation is key to hair follicle (HF) induction ability of dermal papilla (DP) cells and neogenesis of HF can be achieved by transplanting DP microtissues. However, there is currently lack of a suitable system that allows efficient production of DP microtissues and analysis of DP self-aggregation in vitro. We demonstrate that, at a higher seeding cell density, poly(ethylene-co-vinyl alcohol) (EVAL) membranes facilitate DP self-assembly into many compact spheroidal microtissues that are able to induce new HFs. This self-assembling process is associated with an enhanced cell movement and a declined cell-substrate adhesivity on EVAL. A compromised cell growth is also revealed on EVAL. On the contrary, a more adherent surface allows faster cell expansion but maintains DP cells in a flat morphology. Dynamically, cell migration, intercellular collision and intercellular adhesion contribute to DP microtissue formation on EVAL. Our results suggest that, for large-scale production of DP microtissues for HF regeneration, an adhesive surface is needed for quick cell expansion and a biomaterial with a lower adhesivity is required for self-aggregation. In addition, this system can be a model for investigation of DP self-aggregation in vitro.
\end{abstract}

(c) 2008 Elsevier Ltd. All rights reserved.

\section{Introduction}

Destruction and loss of hair follicles (HF) is a common disorder and often causes great psychosocial distress to the affected individuals. Autologous HF transplantation is the current treatment for such disorders [1]. In autologous HF transplantation, the treatment effect relies on the redistribution of remaining HFs, and thousands of HFs are often needed to achieve a cosmetically favorable appearance. In severe cases of hair loss in which appropriate number of HFs cannot be obtained, treatment by neogenesis of $\mathrm{HF}$ via bioengineering is a promising alternative [2].

Structurally, the HF can be divided into several distinctive structures including outer root sheath, inner root sheath, hair shaft, hair matrix, connective tissue sheath, and dermal papilla (DP) [2,3]. HF stem cells, residing in the bulge, can respond to signals in the proliferative stage of HF (anagen) by traveling down toward the hair matrix [4-6]. Division and lineage restricted differentiation of stem cells or transient amplifying cells in the hair matrix give rise to cells which form the concentric layered structures in the hair shaft and root sheaths. Treatment of hair loss can be theoretically

\footnotetext{
* Corresponding author. Institute of Biomedical Engineering, College of Medicine and College of Engineering, National Taiwan University, No. 1, Sec. 1, Jen-Ai Road, Taipei 100, Taiwan. Tel.: +886223562141; fax: +886223934177.

E-mail address: drsjlin@ntu.edu.tw (S.-J. Lin).
}

achieved by transplanting HFs that are regenerated in vitro [2]. Unlike other fields of tissue reconstruction, such as adipose tissue and cartilage reconstruction which involves only one type of cells, production of human HFs in vitro by inducing cultured epithelial cells into a complex HF mini-organ is very challenging [2]. Though organ culture of excised HFs in vitro has been demonstrated [7-9], efficient neogenesis of human HFs in adult life in vitro has not been achieved.

Another approach for HF bioengineering is to generate environments that allow skin to simulate the complex HF morphogenic process in embryological stage [2]. One particular subject regarding this is the dominant role of DP cells in guiding the non-follicular epidermis to develop into HF structures [2]. During the initial stage of HF morphogenesis, DP cells self-aggregate in the dermis and play a vital role in guiding the epidermal placode to develop into follicular structures $[2,3,10]$. It was initially demonstrated that freshly isolated DP can induce new HFs when it is properly placed in the skin in rodents [11-14]. However, to generate a large number of new HFs, DP cells should be expanded in vitro. The in vitro expansion of DP cells was first achieved by Jahoda and Oliver $[15,16]$. The same group and other researchers have also demonstrated that cultured DP cells also retain the ability of inducing new HFs when they are transplanted in close proximity to the epidermis [17-21].

Of note is that the ability of DP cells to induce new HFs is dependent on their intercellular organization. Physiologically, DP cells 
are aggregated in the hair bulb. When they are cultured in vitro on conventional culture plates, they show a tendency to aggregate [15-17]. The HF induction activity is only preserved when they are transplanted to the subepidermal space as dense aggregates.

Therefore, neogenesis of HF can be achieved by transplanting cultured DP cells as dense multicellular aggregates or microtissues $[2,22-24]$. However, high efficiency of DP expansion and HF neogenesis should be achieved before such procedures can be put into clinical applications. In addition to the large number of new HFs required, HFs should also be regenerated with a natural density and spacing on the desired body surface. To solve the above-mentioned issues in HF engineering, we can employ a three-step approach. First, DP cells are expanded in vitro. The method utilized should be able to expand a large number of DPs within an acceptable period. Second, DP cells are cultivated into dense microtissues. Since thousands of DP microtissues are needed, the method used in this step is also a key to the efficiency of the entire process. Lastly, DP cells are transplanted with desired spacing to regenerate HFs. The expansion of DP cells has been demonstrated by explant culture on conventional culture plates [15-17]. However, there is currently lack of an efficient method to cultivate DP cells into dense multicellular aggregates on a large scale for the purpose of HF engineering. A two-step rotation and floatation method has been employed to generate tissues with limited follicular differentiation by using single cells isolated from the lip skin of fetal rats, but the method is labor taking and cells from adult rats fail to aggregate into microtissues in this system [25,26].

We have shown that cells can self-assemble into dense spheroids on controlled biomaterial surfaces [27-29]. Up to date, the interaction of DP with biomaterials has been rarely examined and the ability of controlled biomaterial surfaces to enhance the selfassembly of DP cells into microtissues has not been tested. Though self-aggregation of DP cells is essential for HF morphogenesis and physiology, the detailed dynamics and mechanism regarding this self-assembling behavior have not been investigated in detail. Establishing an in vitro model for DP self-aggregation may contribute to researches in this field.

In this work, we describe the behavior of DP cells on poly(ethylene-co-vinyl alcohol) (EVAL) membrane surface, especially the spontaneous growth of DP cells into spheroidal microtissues that are able to induce new HFs. This self-aggregation is associated with a higher local cell density, relatively weakened cell-substrate adhesivity and enhanced cell migration on EVAL. Our results suggest that an adhesive biomaterial is suitable for quick expansion of DP cells and a relatively low-adhesive surface is required for DP aggregation. In addition to HF engineering, this system can also help to analyze the self-aggregation behavior of DP cells.

\section{Materials and methods}

\subsection{Poly(ethylene-co-vinyl alcohol) (EVAL) membrane preparation}

Commercially available EVAL (E105A, Kuraray, Japan, 56 mol\% vinyl alcohol) was used in this study. EVAL membrane with a dense structure was prepared as previously described $[30,31]$. The EVAL solution was prepared by dissolving EVAL in dimethyl sulfoxide (Merck, Germany) to a final concentration of $20 \mathrm{wt} . \%$ at $60{ }^{\circ} \mathrm{C}$ in a water bath. The EVAL solution was cast on a glass plate with a casting knife and then the glass plate was dried at $60^{\circ} \mathrm{C}$ in the oven overnight. The glass plate was soaked in distilled deionized water at room temperature until the membrane spontaneously detached from the glass plate. The prepared EVAL membranes were transparent and allowed direct observation of cells.

\subsection{Cell culture}

The experimental protocols involving animals were approved by our Institutional Animal Care and Use Committee. Primary culture of DP cells was performed as previously described with modifications [32]. Vibrissal HFs were isolated by scissors and forceps from skin specimens from cheeks of Wistar rats in Dulbecco's Modified Eagle's Medium (DMEM) (Gibco) supplemented with 1-fold concentrated Antibiotic-Antimycotic (Gibco). To isolate the DPs, hair bulbs were cut with scissors and incubated in collagenase I solution (Sigma, USA; $2 \mathrm{mg} / \mathrm{ml}$ ) at $37^{\circ} \mathrm{C}$ for $3 \mathrm{~h}$. After centrifugation, the supernatant was discarded and the cell pellet was resuspended in DMEM in a culture dish (Corning Incorporated, USA). DPs were isolated directly under an inverse phase-contrast microscope by careful pipetting. Up to 10 DPs were transferred to a $25-\mathrm{cm}^{2}$ culture flask (TPP, Switzerland) in $5 \mathrm{ml}$ DMEM containing $20 \%(\mathrm{v} / \mathrm{v})$ fetal bovine serum (FBS) (Biological Industries, Israel) and 1-fold concentrated Antibiotic-Antimycotic (Gibco). Subsequently, the flask was moved to a $37^{\circ} \mathrm{C}$ incubator and left untouched for about 7 days when cell migration out of DP explants was apparent. The growth medium was then refreshed every 3 days. The DP cells were permitted to expand until explants began to merge, and then were subcultured by detachment with $0.05 \%$ trypsin/EDTA (Gibco) and transferred to a 75 $\mathrm{cm}^{2}$ culture flask (Orange Scientific, Belgium), i.e. passage 1. Approximately, $8 \times 10^{6}$ cells could be obtained at passage 3 within 4 weeks after the initiation of primary culture and cells at passage 3 were used for the following experiments.

\subsection{Cell attachment and cell growth}

For determination of the cell attachment and growth, the prepared membranes, $15 \mathrm{~mm}$ in diameter, were placed in 24-well tissue culture polystyrene plate (TCPS) (Costar, USA). A Teflon ring, $15 \mathrm{~mm}$ in diameter, was placed on each of the tested membranes in the wells to prevent them from floating. Membranes and Teflon rings were sterilized in $70 \%$ alcohol overnight and rinsed extensively with phosphate buffered saline (PBS), followed by irradiation of ultraviolet light overnight. For controls, empty TCPS plates were treated the same as the plates containing EVAL membranes. Subsequently, $1 \mathrm{ml}$ of culture medium (90\% DMEM $+10 \%$ FBS) of cell suspension containing $20 \times 10^{3}$ cells was added to each well and maintained at $37^{\circ} \mathrm{C}, 5 \% \mathrm{CO}_{2}$.

For the measurement of cell adhesion to substrate, non-adherent cells were washed away by PBS at 2 and $6 \mathrm{~h}$ after cell seeding. Attached cells were detached by $0.05 \%$ trypsin/EDTA and counted by use of a hemacytometer.

Quantitative analysis of cell growth on EVAL membranes was determined by formazan conversion assays $1,5,9$, and 13 days after seeding as previously described $[28,31]$. The optical density of the formazan solution was read on an ELISA plate reader (ELX800, BIOTEK) at $570 \mathrm{~nm}$.

\subsection{Determination of conditions that yield DP microtissues}

For determination of appropriate seeding cell numbers that yield DP microtissues, $1 \mathrm{ml}$ of DP cell suspension in culture medium containing the cell number of $10 \times 10^{3}, 20 \times 10^{3}, 40 \times 10^{3}, 80 \times 10^{3}$, and $160 \times 10^{3}$, respectively, was added to each well $\left(1.9 \mathrm{~cm}^{2} /\right.$ well $)$ containing an EVAL membrane and maintained at $37{ }^{\circ} \mathrm{C}, 5 \% \mathrm{CO}_{2}$. For controls, empty TCPS plates were used for cell culture. Special attention was taken to make sure that DP cells were seeded as single cells. The morphologies of cells were recorded by a digital camera coupled to an inverse phase-contrast microscope.

To test whether overall cell number or local cell density is the main factor for DP microtissue formation, we seeded the same total cell number of $160 \times 10^{3}$ within $2.5 \mathrm{ml}$ medium on 6-welled $\left(9.5 \mathrm{~cm}^{2}\right), 24$-welled $\left(1.9 \mathrm{~cm}^{2}\right)$, and 48 -welled $\left(0.95 \mathrm{~cm}^{2}\right)$ plates containing EVAL membranes. On the other hand, we varied the seeding cell numbers in the $2.5 \mathrm{ml}$ medium to obtain a constant seeding cell density of $84 \times 10^{3}$ cells $/ \mathrm{cm}^{2}$ on 6-welled $\left(9.5 \mathrm{~cm}^{2}\right), 24$-welled $\left(1.9 \mathrm{~cm}^{2}\right)$, and 48 -welled $\left(0.95 \mathrm{~cm}^{2}\right)$ plates containing EVAL membranes. Empty TCPS plates were used as controls.

\subsection{Viability of DP microtissues}

After 5 days in culture, DP microtissues were removed carefully from EVAL surfaces by a pipette. The microtissues were transferred to TCPS wells and cultured for 8 days. The morphologies of cells were recorded under an inverse phase-contrast microscope.

In a parallel experiment, we compared the viability of microtissues obtained on EVAL and spheroids generated by hanging drop method [24]. In the hanging drop method, each hanging drop contains $20 \mu$ l of culture medium and $1 \times 10^{3}$ DP cells on the roof of a 3.5 -cm culture dish (Corning Incorporated, USA). After 5 days in culture, microtissues obtained on EVAL and spheroids from hanging drop method were trypsinized into single cells and the viability was determined by trypan blue exclusion test [28].

\subsection{Morphology, molecular markers and HF induction ability of DP microtissues}

Microtissues formed on EVAL after 5 days in culture were used in the following examinations. For morphological observations, the cells adhering to the membranes were processed for scanning electron microscopic examination (Hitachi S-2600H) as previously described [27]. For histological examination, the DP microtissues were fixed in $10 \%$ buffered formalin solution for $30 \mathrm{~min}$ and further processed for histological examinations with hematoxylin and eosin stains as described [28].

The preservation of DP molecular markers, including NCAM and $\alpha$-smooth muscle actin, [22,33-35], was examined by immunofluorescence. Cells were fixed with $4 \%$ paraformaldehyde in PBS for $20 \mathrm{~min}$ at $4{ }^{\circ} \mathrm{C}$, washed twice in $4{ }^{\circ} \mathrm{C}$ PBS, treated with $0.1 \%$ Triton-X 100 in PBS for 5 min at room temperature and washed 
twice again. Before incubation with primary antibodies, cultured cells were incubated with $10 \%$ BSA (Sigma) for $10 \mathrm{~min}$. Subsequently, the cells were incubated in monoclonal anti- $\alpha$-smooth muscle actin antibody solution (Sigma; $5 \mu \mathrm{g} / \mathrm{ml}$ in $90 \%$ PBS $+10 \%$ BSA) overnight at $4{ }^{\circ} \mathrm{C}$, and the cells were washed twice in PBS. FITCconjugated goat secondary antibody against mouse IgG (Leinco Technologies Inc. USA; $10 \mu \mathrm{g} / \mathrm{ml}$ in PBS) was added for $30 \mathrm{~min}$ at room temperature and then the specimen was washed twice in PBS. Similarly, for NCAM staining, cells were incubated in polycloncal anti-NCAM antibody solution (CEMICON; $2 \mu \mathrm{g} / \mathrm{ml}$ in $90 \%$ PBS $+10 \%$ BSA) and FITC-conjugated donkey secondary antibody against rabbit IgC (CHEMICON; $10 \mu \mathrm{g} / \mathrm{ml}$ in PBS) following the above-mentioned steps except the treatment with Triton-X 100. The samples were mounted and examined under a fluorescent microscope (Axiovert $200 \mathrm{M}$, Carl Zeiss, Inc.) and a confocal microscope (Meta 510, Carl Zeiss, Germany). For detection of another marker of DP cells, i.e. the alkaline phosphatase activity [21,36], DP cells cultured on EVAL for 5 days were fixed in $4 \%$ paraformaldehyde for $20 \mathrm{~min}$, washed in PBS, incubated for $30 \mathrm{~min}$ in the developing solution routinely used for alkaline phosphatase as described [37].

To determine the ability of DP microtissues to induce new HFs, patch assays were performed as previously described [38]. Truncal skin was excised from newborn mice (C57BL/6) and incubated in PBS containing Dispase $(2.5 \mathrm{mg} / \mathrm{ml}$, Invitrogen, Carlsbad, CA) at $4{ }^{\circ} \mathrm{C}$ overnight. Epidermal cells and dermal cells were then isolated as previously described [39]. HF induction ability was assayed in male nude (nu/nu) mice (National Laboratory Animal Center, Taipei, Taiwan) at 7-12 weeks of age. DP microtissues could be detached from EVAL by gentle pipetting and were collected from ten $1.9-\mathrm{cm}^{2}$ wells containing EVAL membranes 5 days after seeding $\left(160 \times 10^{3}\right.$ cells/well $)$. The DP microtissues were mixed with newborn C57BL/6 epidermal cells $\left(1.6 \times 10^{6}\right.$ cells) in $200 \mu$ l DMEM and injected (23-gauge needle) into the hypodermis of anesthetized nude mice (ketamine, $100 \mathrm{mg} / \mathrm{kg}$ ). For negative controls, only C57BL/ 6 epidermal cells $\left(1.6 \times 10^{6}\right.$ cells $)$ were injected. As positive controls, dermal cells $\left(1.6 \times 10^{6}\right.$ cells $)$ and epidermal cells $\left(1.6 \times 10^{6}\right.$ cells $)$ from newborn C57BL/6 mice were mixed for injection. Two weeks after injection, the skin was excised and HF formation was examined under a dissecting microscope. For histological examinations, the specimens were fixed in $10 \%$ formalin and further processed for hematoxylin and eosin staining.

2.7. Time-lapse microscopy, cell migration and dynamic process of microtissue formation

For measurement of the cell motility on EVAL and TCPS, DP cells were seeded at a low seeding density of $5 \times 10^{3}$ cells $/ \mathrm{cm}^{2}$. Twelve hours after seeding, DP cell migration was then traced by an inverse phase-contrast microscope-based time-lapse microscopic system (Axiovert 200 m; Carl Zeiss, Gottingen, Germany) equipped with a temperature, humidity and $\mathrm{CO}_{2}$ controlled incubator and a CCD Camera (CoolSNAP HQ2, Roper Scientific, Photometrics, Tucson, AZ, USA).

The images were recorded at an interval of $10 \mathrm{~min}$ and visualized using the computer software (MetaMorph v.7.1.2, Universal Imaging Corporation, Downingtown, PA, USA). Cell migration was assessed by tracing the movement of the nucleus by software (MetaMorph Offline, Universal Imaging Corporation, Downingtown, PA, USA). In each experiment, 16 motile cells were randomly selected and followed by time-lapse photography for $4 \mathrm{~h}$.

For observation of the dynamic process of DP microtissue formation, the condition for time-lapse recording was the same as that for assessing the motile activity of DP cells except that the cells were seeded at a density of $84 \times 10^{3}$ cells $/ \mathrm{cm}^{2}$ and the recording started $24 \mathrm{~h}$ after seeding. The images were taken at an interval of $30 \mathrm{~min}$ and the period for the recording was $48 \mathrm{~h}$.

\section{Results}

\subsection{The formation of multicellular DP microtissues on EVAL membranes at higher seeding cell number}

We find that constant formation of DP microtissues on EVAL is affected by seeding cell numbers. After 1 day in culture, no obvious formation of dense multicellular microtissues is observed on EVAL at all seeding numbers (Fig. 1a, left panel). However, at higher seeding cell numbers, the initial tendency to aggregate can be observed (Fig. 1a, left panel, arrow heads). Cells remain a flat morphology on TCPS surface even at the highest seeding number (Fig. 1a, left panel).

After 3 days in culture, formation of multiple dense DP microtissues can be observed on EVAL (Fig. 1a, central panel). A greater trend for microtissue formation is observed as the seeding number is increased. Constant formation of DP microtissues can be observed at seeding numbers of $80 \times 10^{3} /$ well and $160 \times 10^{3} /$ well (Fig. 1a, central panel, arrows), and the DP microtissues appear to be randomly distributed. At seeding numbers of $40 \times 10^{3} /$ well or less, constant formation of DP microtissue is not observed although a few microtissues can be occasionally observed in repeated experiments (data not shown). At this time, cells still remain a flat morphology on TCPS surface at all seeding numbers.

Maintained in culture for 5 days, dense microtissues can still be observed on EVAL at the seeding numbers of $80 \times 10^{3} /$ well or higher (Fig. 1a, right panel, arrows). Between microtissues, flat DP cells are still present. Similar to the result on day 3, at seeding numbers of $40 \times 10^{3} /$ well or less, only a few microtissues can sometimes be locally observed in repeated experiments (data not shown).

\subsection{Local cell density is the major determinant of DP microtissue formation on EVAL membranes}

The results above can also be interpreted in another way that the cell density is the major determinant of microtissue formation on EVAL surface and DP cells can grow into microtissues at the seeding density of $42 \times 10^{3}$ cells $/ \mathrm{cm}^{2}$ or higher. The occasional microtissue formation at seeding densities lower than $42 \times 10^{3}$ cells $/ \mathrm{cm}^{2}$ may be attributed to initial uneven seeding that leads to local higher cell densities.

To test whether local cell density or the overall cell number is the major factor for microtissue formation, similar numbers of cells are seeded on EVAL of varied surface areas. We also vary the seeding cell numbers to keep the seeding density constant on each EVAL membrane with varied surface areas. When a constant number of $160 \times 10^{3}$ cells/well is used for seeding (Fig. $1 \mathrm{~b}$, the upper three pictures), microtissues can be observed in the 24-welled and 48-welled plates (seeding density of $84 \times 10^{3} \mathrm{cells} / \mathrm{cm}^{2}$ and $168 \times 10^{3}$ cells $/ \mathrm{cm}^{2}$, respectively). No microtissue is observed in the 6 -welled plates (Fig. 1b) (seeding density of $16.8 \times 10^{3}$ cells $/ \mathrm{cm}^{2}$ ). In the parallel experiment in which a constant seeding density of $84 \times 10^{3}$ cells $/ \mathrm{cm}^{2}$ is used for the 6-welled, 24-welled and 48 welled plates (Fig. 1b, the lower three pictures), formation of multicellular DP microtissues can be observed in all cases. The results strengthen the point that cell density is the major determinant of DP microtissue formation on EVAL membranes.

\subsection{Number and size distribution of DP microtissues on EVAL membranes}

We characterize the number and size distribution of the DP microtissues formed on EVAL after 5 days in culture (Table 1). Approximately, the diameter of the microtissues formed on EVAL on day 5 can vary from tens of $\mu \mathrm{m}$ to about $300 \mu \mathrm{m}$. Since the diameters of the freshly isolated DPs of Wistar rats are about 100$200 \mu \mathrm{m}$, microtissues with an average diameter larger than $125 \mu \mathrm{m}$ are calculated. The number of microtissues increases as the seeding number is increased. At the seeding number of $160 \times 10^{3}$, the diameter of the microtissues is mainly within the range of 125$150 \mu \mathrm{m}$. Overall, about 47 microtissues (diameter $>125 \mu \mathrm{m}$ ) can be obtained on an EVAL surface of $1.9 \mathrm{~cm}^{2}$ with a single seeding of $160 \times 10^{3}$ DP cells.

\subsection{Characters of DP microtissues on EVAL}

The scanning electron micrograph shows that the microtissue is a spheroidal structure (Fig. 2). This structure is similar to DPs in vivo, i.e. aggregated as a compact multicellular mass. On the surface of microtissues, the intercellular boundary cannot be clearly delineated. On the periphery of the microtissue, cells with multiple long cell processes can still be observed. When the microtissue is sectioned in histology, the DP microtissue also shows a compact structure (Fig. 2). 
a
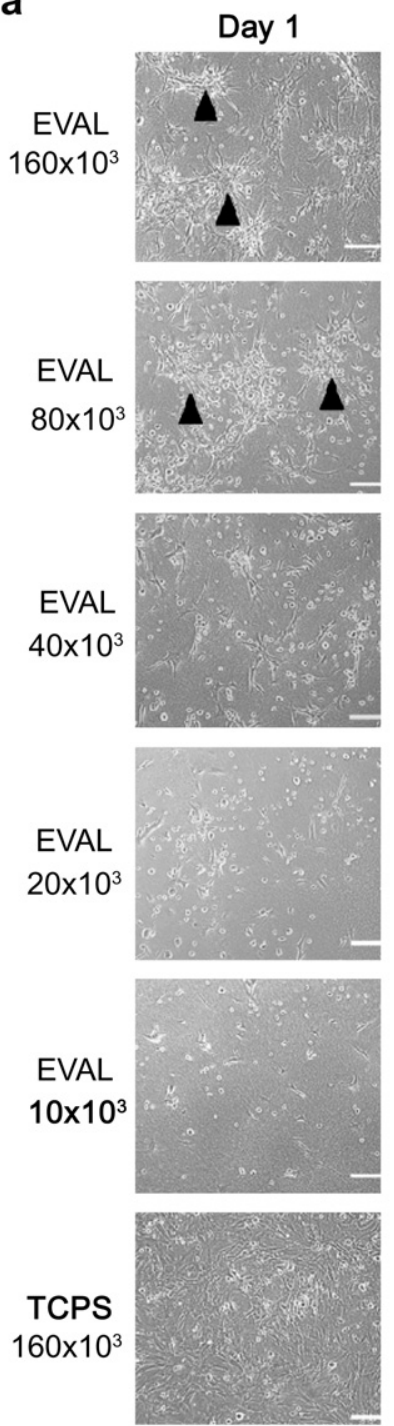

Day 3
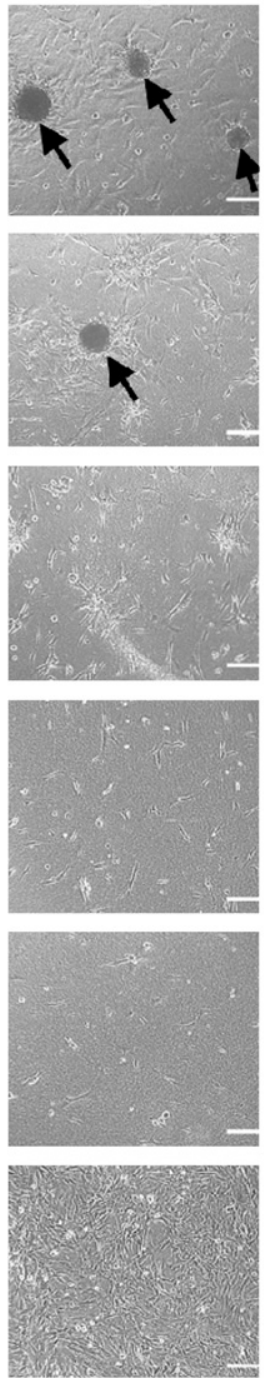

Day 5
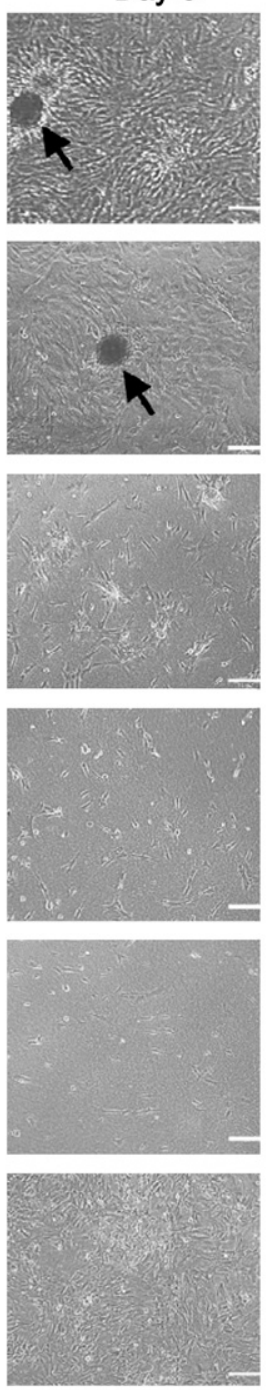

b
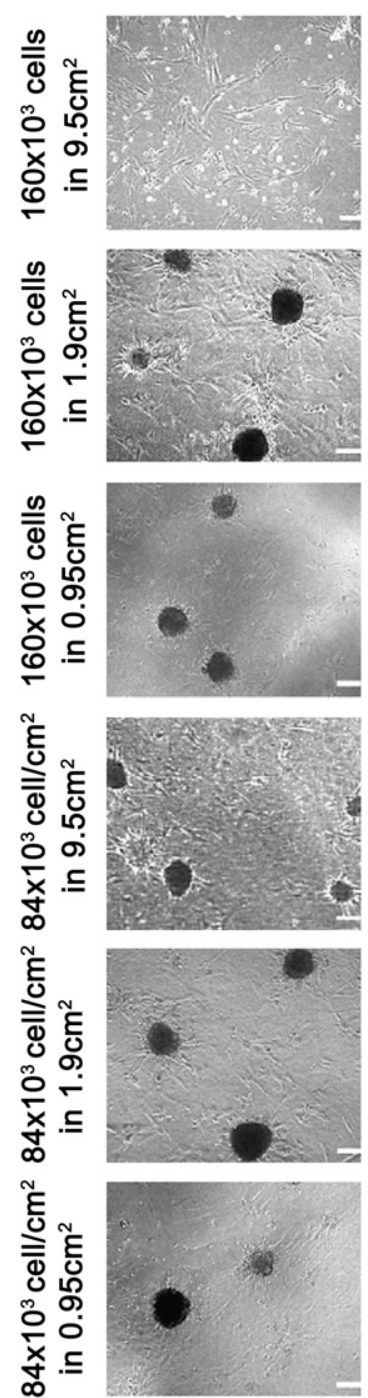

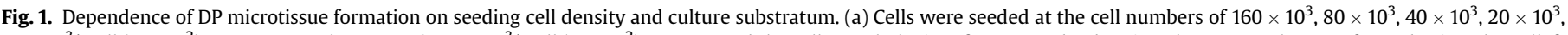

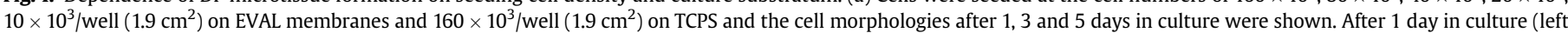

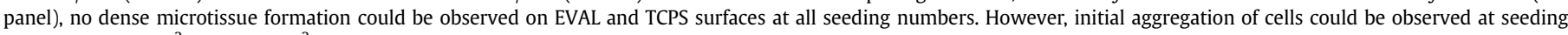

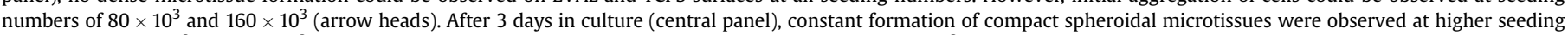

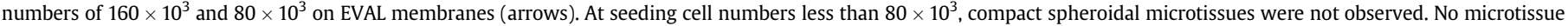

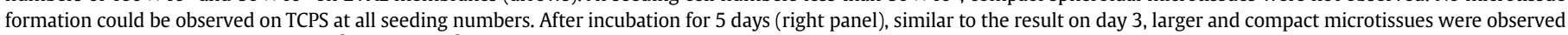

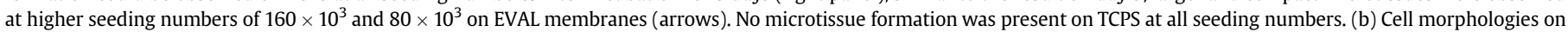

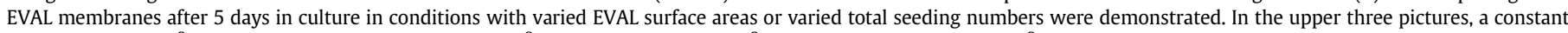

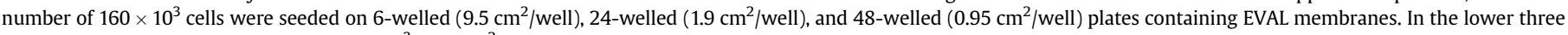

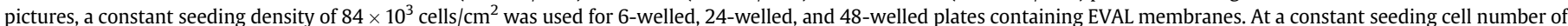

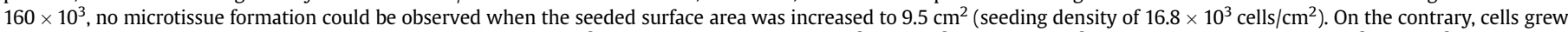

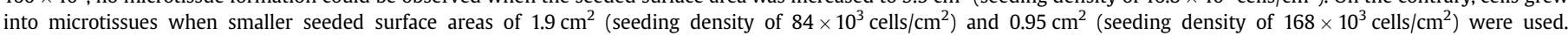

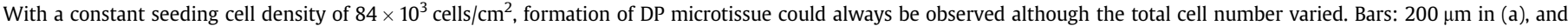
$100 \mu \mathrm{m}$ in (b).

Table 1

The dependence of number and size distribution of DP microtissues on seeding cell numbers on EVAL surface

\begin{tabular}{|c|c|c|c|c|c|}
\hline \multirow[t]{2}{*}{ Diameter of microtissue $(\mu \mathrm{m})$} & \multicolumn{5}{|c|}{ Number of microtissue at different seeding cell numbers } \\
\hline & $160 \times 10^{3}$ cells/walls & $80 \times 10^{3}$ cells/walls & $40 \times 10^{3}$ cells/walls & $20 \times 10^{3}$ cells/walls & $10 \times 10^{3}$ cells/walls \\
\hline$>200$ & $2.67 \pm 0.29$ & 0 & 0 & 0 & 0 \\
\hline $150-200$ & $7.33 \pm 1.89$ & $0.67 \pm 0.580$ & 0 & 0 & 0 \\
\hline $125-150$ & $37.33 \pm 3.25$ & $9.00 \pm 1.73$ & $2.67 \pm 0.76$ & 0 & 0 \\
\hline Total $(>125)$ & $47.33 \pm 1.89$ & $9.67 \pm 2.31$ & $2.67 \pm 0.76$ & 0 & 0 \\
\hline
\end{tabular}

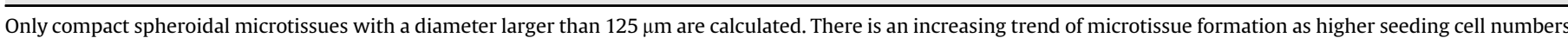

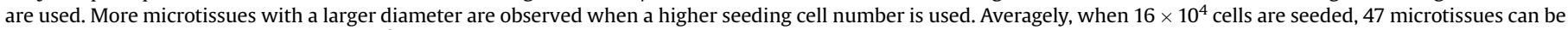
obtained. A seeding cell number of $4 \times 10^{4}$ cells or less yields no or few microtissues. 

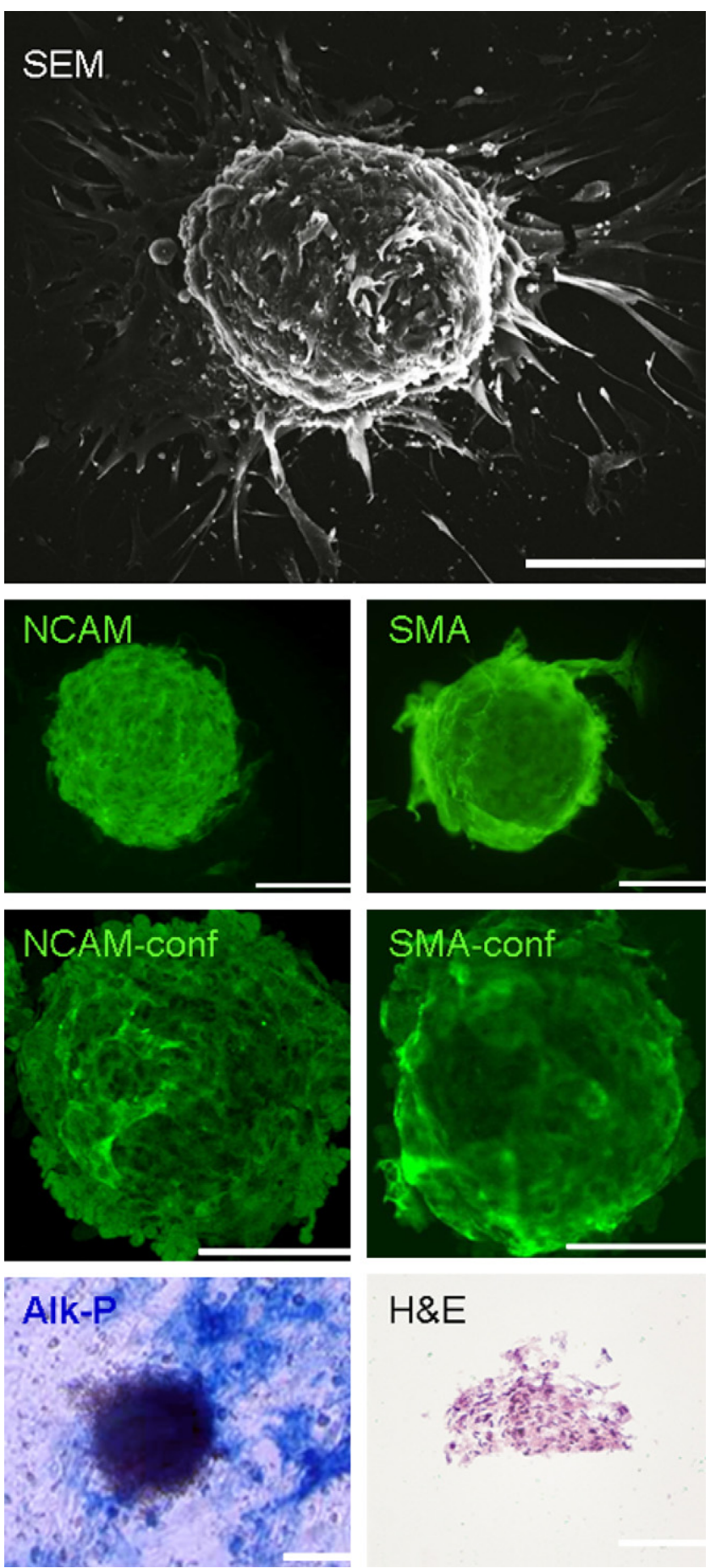

Fig. 2. Morphology, preservation of molecular markers and histology of DP microtissues. Scanning electron micrograph (SEM) shows the DP microtissue displays a three-dimensional compact spheroidal morphology. The cells on the periphery of the microtissue still adopt a flat morphology with multiple cell processes. Immunofluorescent micrographs (NCAM and SMA) show that the expression of NCAM and $\alpha$ smooth muscle actin (SMA) is preserved in DP microtissues. The confocal images taken from the plane of greatest diameter of microtissues also show positive staining for NCAM (NCAM-conf) and $\alpha$-smooth muscle actin (SMA-conf) in the interior cells of the microtissues. Higher alkaline phosphatase enzyme activity (Alk-P, blue color) is detected in DP microtissues and in cells with initial aggregation. Histology (H\&E) from a vertical section shows a compact hemispherical structure of a DP microtissue (hematoxylin and eosin stain). The underlying EVAL membrane is detached from the DP microtissue during the fixation and staining process. Bars: $100 \mu \mathrm{m}$.

We then examine the preservation of the phenotype of DP cells in microtissues. The expression of two markers of DP cells, NCAM and $\alpha$-smooth muscle actin [22,33-35], is well preserved in microtissues (Fig. 2). In the confocal micrographs, the interior cells of DP microtissues are still positive for the expression of NCAM and $\alpha$-smooth muscle actin (Fig. 2). Similar to the result in histology, the confocal micrographs also show that the cells are tightly packed in the DP microtissues. As to alkaline phosphatase which is believed to be correlated with HF induction ability of DP cells [21,36], higher enzyme activity is detected in DP microtissues and cells with initial aggregation as compared with monolayered cells (Fig. 2).

\subsection{High viability of cells in DP microtissues and the transformable cell morphology on different substratum}

After the microtissues are reseeded on TCPS surface, the cells are able to grow and migrate out of the microtissues on day 1 (Fig. 3). The microtissues start to disintegrate on day 2 and further grow into confluent flat cells on day 8 (Fig. 3). This observation indicates that the cells in DP microtissues are viable and the morphologies of DP cells are transformable on different culture substratum.

We then quantify the cell viability and reveal that the cell viability in DP microtissues obtained on EVAL is different from that in DP spheroids generated by hanging drop method [24]. The cell viability in DP microtissues on EVAL is much higher than that in DP spheroids generated by hanging drop method (mean viability is $96.39 \pm 0.09$ and $53.3 \pm 3.3 \%$, respectively; $p$-value $<0.001$ ). The result suggests that the viability of cells in microtissues can be affected by the method employed to generate microtissues.

\subsection{DP microtissues are able to induce new HFs}

We then ask whether DP microtissues generated on EVAL retain the HF induction activity. When DP microtissues are mixed with newborn mouse epidermal cells and injected into the hypodermis of nude mice in a patch assay, similar to positive controls (data not shown), they are able to induce new HFs (Fig. 4). In the negative controls, no HF is revealed (data not shown). The results show that, in addition to preserving molecular markers, DP microtissues generated on EVAL still retain HF induction ability, the signature function of DP cells.

\subsection{Declined adhesivity and enhanced cell migration on EVAL membranes}

The adhesion of DP cells to EVAL surface is determined 2 and $6 \mathrm{~h}$ after seeding. As shown in Fig. 5a, at $2 \mathrm{~h}$, the number of cells adhered to EVAL ( $4690 \pm 568$ cells/well) is about $47.49 \%$ of that attached to TCPS surface ( $9876 \pm 1173$ cells/well). From 2 to $6 \mathrm{~h}$, the cells attached to EVAL surface increase from $4690 \pm 568$ cells/well to $6634 \pm 612$ cells/well. However, the number of cells attached to EVAL surface is still less than that to TCPS surface (66.89\% of that attached to TCPS) at $6 \mathrm{~h}$. This result shows that there is compromised adhesivity of DP cells to EVAL as compared with that to TCPS [40].

This declined adhesivity of DP cells to EVAL surface is also in accordance with the cell morphologies 1 day after seeding (Fig. 5b). Most cells on TCPS surface have multiple processes (Fig. 5b, left panel) but cells have fewer cell processes or display a bipolar morphology on EVAL surfaces (Fig. 5b, right panel).

The time-lapse microscopy also reveals that cells display different motility on these two surfaces. DP cells are more motile on EVAL as compared with that on TCPS (Fig. 5c). Quantitatively, the length of the path traveled by each motile cell on EVAL is significantly longer than that on TCPS $(22.17 \pm 7.16 \mu \mathrm{m}$ on EVAL and $13.69 \pm 3.74 \mu \mathrm{m}$ on TCPS over a period of $4 \mathrm{~h}, p$-value $<0.001$ ). This indicates that EVAL is able to enhance the motility of DP cells. 

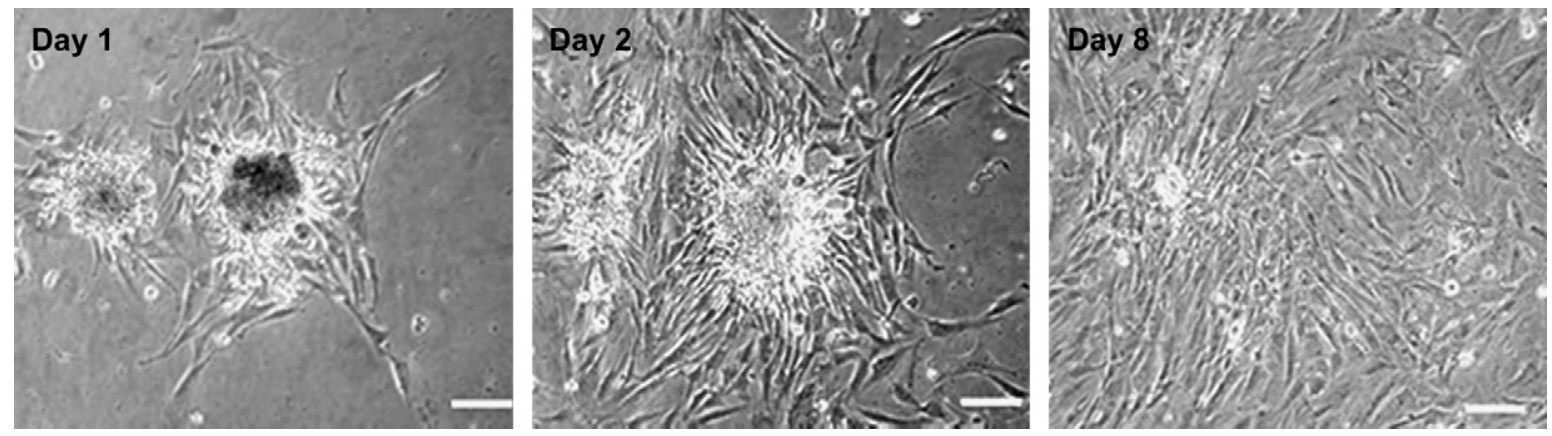

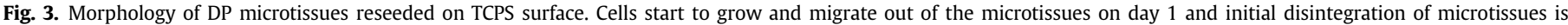

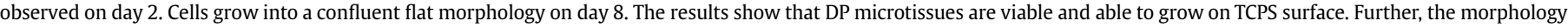
of DP cells can be reversed from aggregated microtissues to a conventional flat morphology with multiple cell processes on TCPS (bars: $100 \mu$ m).

\subsection{Dynamics of DP microtissue formation on EVAL membranes}

The time-lapse micrographs of DP microtissue formation on EVAL is shown in Fig. 6 (left panel). Initially, DP cells are quite motile. In areas with higher local cell densities, frequent intercellular contact or collision occurs. More intercellular collision leads to initial multilayered aggregation of DP cells (Fig. 6, left
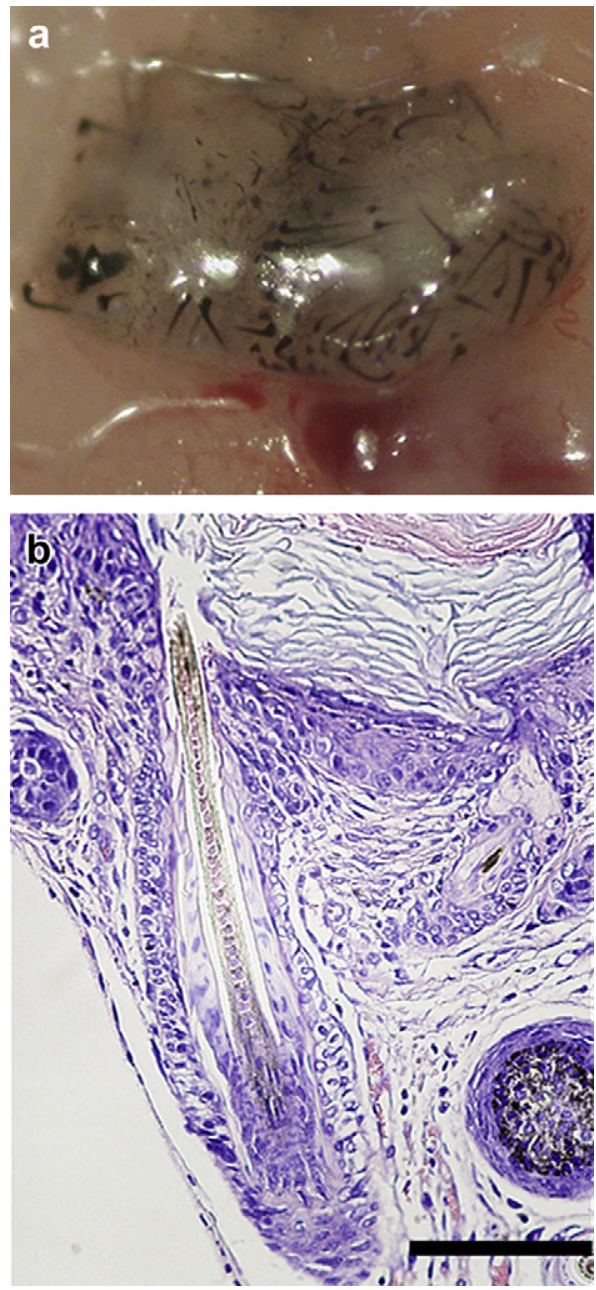

Fig. 4. Ability of DP microtissues to induce new HFs. (a) Photographs of induced HFs in a patch assay. Two weeks after the mixture of epidermal cells and DP microtissues was injected in a patch assay; many pigmented HFs could be observed in the hypodermis of a nude mouse. (b) Histology of induced HFs in the patch assay. Complete structures of a functional HF including hair shaft, root sheaths, hair matrix and DP could be demonstrated in the regenerated HF. Sebaceous gland was also revealed below the epidermis in the hair follicle on the right side. Hematoxylin and eosin stain. Bar: $100 \mu \mathrm{m}$. panel, $36 \mathrm{~h}$, arrow head). Cells outside the aggregation are still flat in morphology with long cell processes. From 42 to $54 \mathrm{~h}$, the aggregation becomes more evident (Fig. 6, left panel, 42-54 h, arrow heads) and these aggregates further grow into compact spheroidal microtissues (Fig. 6, left panel, 54 and $60 \mathrm{~h}$, arrows).

On the contrary, DP cells on the TCPS are much less motile in the time-lapse recording (Fig. 6, right panel). When the cell processes from different cells contact, DP cells show little tendency to aggregate into microtissues. During the entire recording period, the cell number increases and DP cells remain flat in morphology.

\subsection{Enhanced cell growth on the adhesive surface}

Up to date, little is known about the difference in DP cell growth on biomaterial surfaces of different cell-substrate adhesivity. We examine the DP cell growth on EVAL and TCPS surface. Cells are seeded at a lower number so that no DP microtissue forms on EVAL in culture. As shown in Fig. 7, cell growth is enhanced at all time points on TCPS as compared with that on EVAL. Initially on day 1 , a larger cell population is revealed on TCPS surface. Considering the intrinsic low proliferation rate of DP cells, this could reflect a higher cell number attached to TCPS after seeding. The cells on TCPS continuously increase from day 1 to day 13 . On the contrary, the lower attachment due to the decreased cell-substrate adhesivity may lead to a decreased cell number on EVAL on day 1. Furthermore, there is a delay in cell growth on EVAL before day 5 and significant cell growth is only observed from day 5 to day 13 . The result indicates that DP cells are able to proliferate on EVAL surfaces after an initial quiescent period.

\section{Discussion}

The substrate can influence the morphology, intercellular organization and also the function of cells [28,29,41-44]. Conventionally, cells are usually cultured as monolayer in vitro. However, cells can also be maintained as dense aggregates or microtissues which have a wide application in cancer research $[45,46]$. The response of cancer microtissues to chemotherapy and radiotherapy is different from that of monolayered cells [46], and microtissues in vitro may be a more appropriate model to simulate the cell behavior in vivo. In addition, for certain cell types, specific cellular functions in vitro can only be preserved when cells are cultured into microtissues. For example, the ossification can only be achieved when osteocytes are cultured into aggregates [47]. Hepatocyte is another example and its albumin production and detoxificatory ability can only be enhanced in spheroids in vitro $[48,49]$.

DP cells also require a three-dimensional organization to preserve its HF induction ability. It has been shown that the HF induction activity of cultured DP cells can be retained when they are 


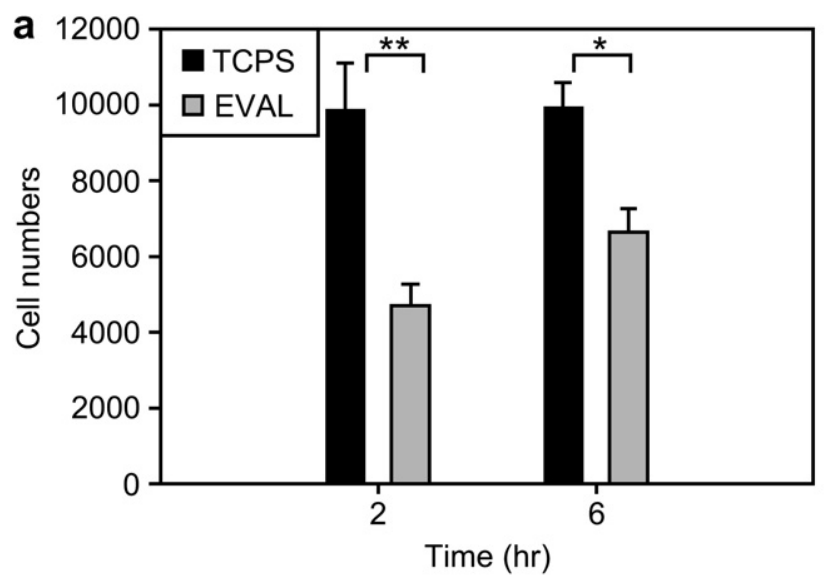

b

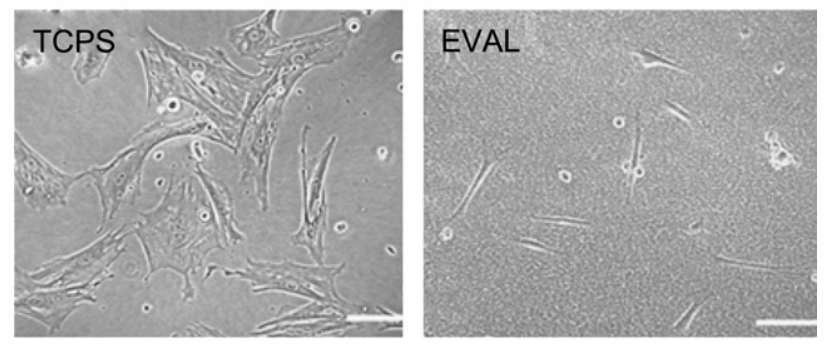

C

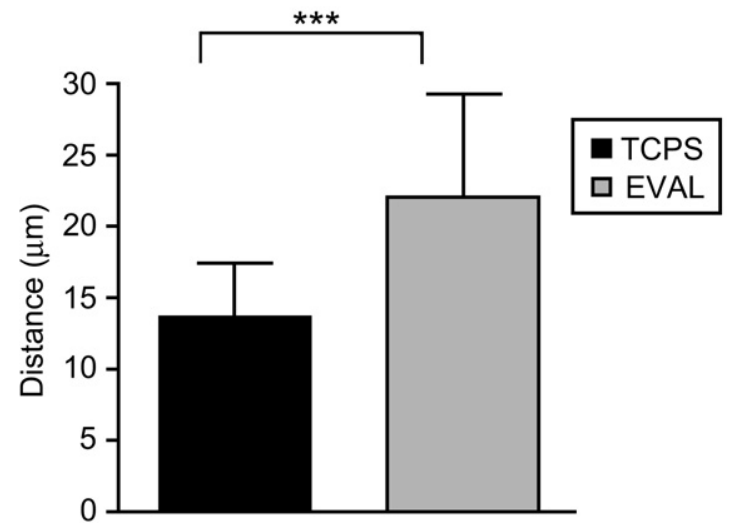

Fig. 5. Cell-substrate adhesivity, cell morphology and cell motility on TCPS and EVAL. (a) Cell-substrate adhesivity is determined by cell attachment at 2 and $6 \mathrm{~h}$ after seeding. The cell numbers attached to EVAL are significantly lower than that to TCPS at 2 and $6 \mathrm{~h}$. The result indicates that DP cells have a compromised adhesivity to EVAL as compared with that to TCPS. (Student's $t$-test is performed for comparison; ${ }^{*} p<0.05$, ${ }^{* *} p<0.01$.) (b) Cell morphologies on TCPS and EVAL 1 day after seeding. Cells are flat with a larger surface area and multiple cell processes on TCPS (left panel). On the contrary, cells are spindle-shaped with fewer cell processes on EVAL and many cells still have a round morphology (right panel). Bars: $100 \mu \mathrm{m}$. (c) Cell migration on EVAL and TCPS. Over a period of $4 \mathrm{~h}$, motile cells on EVAL travel a longer distance than that on TCPS (mean: $22.17 \pm 7.16 \mu \mathrm{m}$ on EVAL and $13.69 \pm 3.74 \mu \mathrm{m}$ on TCPS; Student's $t$-test is performed for comparison, ${ }^{* *} p<0.001$ ).

transplanted as dense suspension or microtissues [17-22]. Even when dermal inductive cells are transplanted as dispersed cells, spontaneous assembling of cells into DP microtissues also precedes the neogenesis of HF structures [38]. The intrinsic aggregative tendency has long been accepted as a major character of DP cells both in vivo and in vitro. However, by use of conventional culture plates, DP cells can hardly grow further into compact multicellular spheroids. Since the interaction of DP cells with biomaterials is rarely investigated, there has been no report of culturing DP cells into microtissues by the self-assembly on a biomaterial surface. We believe that this is the first time to examine experimentally that the formation of DP microtissue can be enhanced on a controlled biomaterial surface.
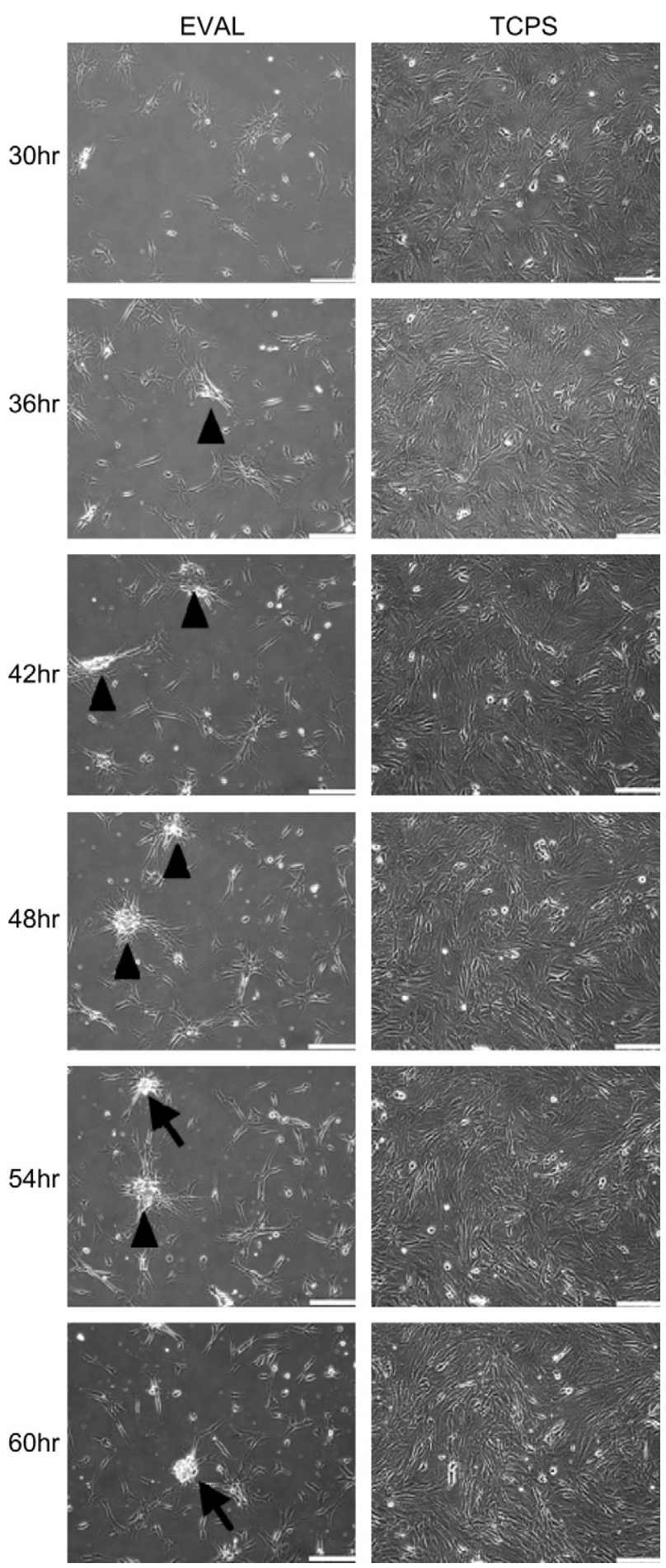

Fig. 6. Time-lapse microscopic recording of cell behavior on EVAL and TCPS. The left panel shows the dynamic process of DP microtissue formation on EVAL from 30 to $60 \mathrm{~h}$ after seeding. Cell behavior on TCPS is shown on the right panel for comparison. Initially, cells attached to EVAL are quite motile and frequent intercellular contact can be observed. In areas where multiple cells contact each other, cells start to aggregate (36$54 \mathrm{~h}$, arrow heads). These aggregates further condense into compact spheroidal microtissues ( 54 and $60 \mathrm{~h}$, arrows). The surrounding flat single cells are gradually merged into the aggregates or microtissues when they contact. On TCPS, cells gradually grow into confluency due to cell proliferation and no microtissue is observed. Compared with cells on EVAL, cells are less motile on TCPS. Bars: $200 \mu \mathrm{m}$.

The mechanism by which different cells employ to aggregate into multicellular microtissues on a biomaterial surface may not be the same. There is evidence that hepatocytes can secrete so called "spheroid forming factors" into the culture medium to enhance 


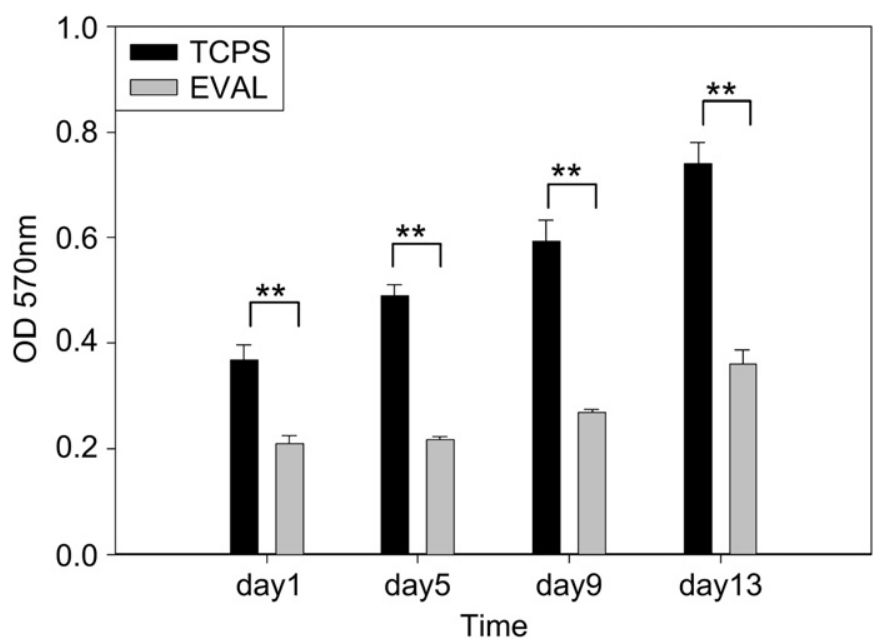

Fig. 7. Cell growth on TCPS and EVAL surfaces. Cell growth determined by formazan conversion is expressed by the optical density (OD) values at $570 \mathrm{~nm}$. At all time points, the TCPS group has a higher OD value. Cells continuously grow on TCPS after seeding, indicated by the continuous increase of formazan conversion. In addition to the overall lower cell growth on EVAL, there is also a delayed cell proliferation on EVAL and the formazan conversion is not significantly increased from day 1 to day 5. Following this quiescent period, cells grow from day 5 to day 13 . The final growth of DP cells on EVAL is still much less than that on TCPS on day 13. (Student's $t$-test is performed for comparison, ${ }^{* *} p<0.01$.)

their self-assembly [50]. When higher cell numbers are present in a unit culture medium volume, more spheroid forming factors produced by cells can ameliorate their self-assembly. However, our results show that the aggregation of DP cells on EVAL is dependent on the local cell density, but not on spheroid forming factors. In Fig. 1, constant formation of DP microtissue can only be observed at a seeding density of $42 \times 10^{3}$ cells $/ \mathrm{cm}^{2}$ or higher. To address this point, by varying the seeding densities under a constant seeding cell number as well as by varying total seeding cell numbers under a constant seeding cell density, we demonstrate that cell density on the biomaterial surface is the major determinant of microtissue formation on EVAL surface (Fig. 1b). The findings indicate that cell density on a smaller scale, or the intercellular distance, is the major determinant of microtissue formation. These results also suggest that, even with very low total seeding cell numbers, DP cells will be able to self-assemble into microtissues on EVAL if they are seeded on a very small area.

Dynamically, growth of cells into spheroidal microtissues on a biomaterial surface can be theoretically achieved in several ways. First, culture substrate may selectively promote clonal proliferation of cells. This hypothesis is unlikely in our case. According to the growth curve in Fig. 7, the initial proliferation of DP cells on EVAL is delayed until they are kept in culture for 5-9 days. Further, if this hypothesis holds, we can expect that DP microtissues can be observed at lower seeding densities. Second, due to the weaker adhesivity of DP cells to EVAL, cells may stay suspended longer in the medium and thereby aggregate after intercellular collision in the medium before they have a chance to adhere to EVAL surface. In other word, DP cells adhere to EVAL surface as aggregates. However, the observation that no spheroids can be seen on day 1 at all seeding densities makes this mechanism unlikely. Lastly, DP cells adhere to the biomaterial as disperse cells and subsequently aggregate on the surface. This mechanism is supported by the results shown in Fig. 1. After 1 day in culture, cells are more evenly distributed on EVAL surface than that during further culture periods. At higher seeding densities, initial aggregation of multilayered cells can be seen on day 1 . When the microtissues form on day 3 , the areas surrounding the microtissues become sparsely populated by DP cells. The observations suggest that the cells translocate and aggregate into microtissues, making the cells sparser on the areas adjacent to the microtissues. This is also supported by the result obtained in the time-lapse recording (Fig. 6), showing that microtissues are formed through the active migration and intercellular adhesion of cells.

Hence, attachment, active cell migration, frequent intercellular collision and intercellular adhesion contribute to the formation of DP microtissues on EVAL surface. This model explains why EVAL can efficiently promote DP microtissue formation at higher cell densities. Since EVAL enhances cell movement, the higher cell migration rate can increase the incidence of intercellular contact or collision. On the contrary, at lower cell densities, i.e. longer intercellular distance, the frequency of intercellular collision is lowered to a level that does not allow the formation of microtissues.

In addition to the intercellular distance and active cell migration, another character of cell-substrate interaction is also vital to the formation of microtissues. According to the differential adhesion hypothesis and our previous reports [27,28,40], the formation of microtissue on biomaterials is dependent on the balance of two competing forces: cell-cell adhesivity and cell-substrate adhesivity. The intrinsic aggregative tendency of DP cells may represent a strong intercellular adhesion of DP cells that help to hold cells together when they collide. The compromised adhesion of cells to EVAL also tilts the balance to a state favorable for DP microtissue formation. This hypothesis can also explain why DP cells fail to form microtissues even at higher seeding densities on TCPS: the cell-cell adhesivity is still unable to overcome the strong adhesivity between DP cells and TCPS. This argument is supported by the result that when DP microtissues are reseeded on TCPS surface which conveys a stronger adhesivity to DP cells, the microtissues gradually disintegrate into flat cells (Fig. 3). It has been shown that the hydrophobicity of culture substratum can affect the cell behavior [31,51,52]. Since EVAL is a random copolymer of hydrophobic ethylene and hydrophilic vinyl alcohol [30,31], it would be very interesting to examine the effect of hydrophobicity of culture substratum on the morphology of DP cells by adjusting the ratio of ethylene and vinyl alcohol monomers in this copolymer [31].

Our results also suggest that an adherent substrate like TCPS is more suitable for DP cell expansion. DP cells can adhere to the surface faster and start to proliferate shortly after they attach to the surface. On the contrary, a relatively non-adherent surface promotes DP cell aggregation. The proliferation of DP cells on the relatively non-adherent surface is delayed for a certain period. The reason for the delay of growth of DP cells on EVAL surface is unclear. Hence, for efficient production of DP microtissues for HF regeneration, DP cells can be expanded first on an adherent surface and then seeded on a relatively non-adherent surface to generate microtissues. Take rat vibrissal DPs for example. We initially use 10 freshly isolated DP for culture and we expand the cells to $8 \times 10^{6}$ within 4 weeks. Theoretically, if these cells are all seeded on EVAL surface at a density $84 \times 10^{3} \mathrm{cells} / \mathrm{cm}^{2}$, we can obtain approximately 2350 DP microtissues with one single seeding. The effort employed in the process, in addition to DP isolation procedures, includes only three trypsinizations during passage and one trypsinization before the cells are seeded on EVAL surface. There is a 235-fold increase in the DP microtissues generated.

In addition to the large-scale production of DP microtissues for HF engineering, our research has other important applications as well. Though it is known that the aggregative nature is vital for the functioning of DP cells, how and by which mechanism DP cells aggregate have not been investigated in detail. Our system can serve as an in vitro model for analysis of the dynamics and molecular events required for the aggregation of DP cells. 


\section{Conclusion}

Self-assembly of DP cells into spheroidal inductive microtissues can be facilitated when cells are seeded at appropriate densities on EVAL surface. Formation of DP microtissue is associated with enhanced cell migration and lower cell-substrate adhesivity on EVAL surface. On the contrary, a more adherent surface, such as TCPS, allows faster DP cell expansion in a monolayered morphology. Our results suggest that, for efficient large-scale production of DP microtissues for HF engineering, cells can be first expanded on more adhesive surface and then transferred to EVAL to facilitate the self-assembly into microtissues. We also characterize the dynamics of DP microtissue formation on EVAL. After cells attach to EVAL active migration, intercellular collision and intercellular aggregation lead to microtissue formation. Our system is of potential to be applied to $\mathrm{HF}$ engineering and the investigation of DP selfaggregation.

\section{Acknowledgements}

The authors thank Dr. Wei-Chou Lin, Department of Pathology, National Taiwan University Hospital, for his help in histological examination and Miss Shu-Chen Shen for her assistance in the experiments employing time-lapse microscopy. The experiments and data analysis of time-lapse microscopy were performed in part through the use of the Cell Imaging Center (Core Lab. 2) in National Taiwan University Hospital. The authors are also grateful to National Taiwan University Hospital (96-S651), National Science Council, Taiwan (NSC95-2314-B-002-127, NSC96-2314-B-002-105, NSC96-2627-B-002-009) and National Health Research Institutes, Taiwan (NHRI-EX97-9714EC) for their financial support.

\section{References}

[1] Orentreich N. Autografts in alopecias and other selected dermatological conditions. Ann N Y Acad Sci 1959;83:463-79.

[2] Stenn KS, Cotsarelis G. Bioengineering the hair follicle: fringe benefits of stem cell technology. Curr Opin Biotechnol 2005;16:493-7.

[3] Philpott M, Paus R. Principles of hair follicle morphogenesis. In: Chuong CM editor. Molecular basis of epithelial appendage morphogenesis. Austin, Texas, USA: R.G. Landers Company; 1998. p. 75-110.

[4] Cotsarelis G. Epithelial stem cells: a folliculocentric view. J Invest Dermatol 2006;126:1459-68.

[5] Blanpain C, Fuchs E. Epidermal stem cells of the skin. Annu Rev Cell Dev Biol 2006;22:339-73.

[6] Oshima H, Rochat A, Kedzia C, Kobayashi K, Barrandon Y. Morphogenesis and renewal of hair follicles from adult multipotent stem cells. Cell 2001;104: 233-45.

[7] Buhl AE, Waldon DJ, Kawabe TT, Holland JM. Minoxidil stimulates mouse vibrissae follicles in organ culture. J Invest Dermatol 1989;92:315-20.

[8] Philpott MP, Green MR, Kealey T. Human hair growth in vitro. J Cell Sci 1990; 97:463-71.

[9] Philpott MP, Green MR, Kealey T. Rat hair follicle growth in vitro. Br J Dermatol 1992;127:600-7.

[10] Millar SE. Molecular mechanisms regulating hair follicle development. J Invest Dermatol 2002;118:216-25.

[11] Oliver RF. The experimental induction of whisker growth in the hooded rat by implantation of dermal papillae. J Embryol Exp Morphol 1967;18: 43-51.

[12] Oliver RF. Ectopic regeneration of whiskers in the hooded rat from implanted lengths of vibrissa follicle wall. J Embryol Exp Morphol 1967;17: 27-34.

[13] Oliver RF. The induction of hair follicle formation in the adult hooded rat by vibrissa dermal papillae. J Embryol Exp Morphol 1970;23:219-36.

[14] Cohen J. The transplantation of individual rat and guineapig whisker papillae. J Embryol Exp Morphol 1961;9:117-27.

[15] Jahoda C, Oliver RF. The growth of vibrissa dermal papilla cells in vitro. Br J Dermatol 1981;105:623-7.

[16] Jahoda CA, Oliver RF. Vibrissa dermal papilla cell aggregative behaviour in vivo and in vitro. J Embryol Exp Morphol 1984;79:211-24.

[17] Jahoda CA, Horne KA, Oliver RF. Induction of hair growth by implantation of cultured dermal papilla cells. Nature 1984;311:560-2.

[18] Jahoda CA, Reynolds AJ, Oliver RF. Induction of hair growth in ear wounds by cultured dermal papilla cells. J Invest Dermatol 1993;101:584-90.
[19] Inamatsu M, Matsuzaki T, Iwanari H, Yoshizato K. Establishment of rat dermal papilla cell lines that sustain the potency to induce hair follicles from afollicular skin. J Invest Dermatol 1998;111:767-75.

[20] Reynolds AJ, Jahoda CA. Cultured dermal papilla cells induce follicle formation and hair growth by transdifferentiation of an adult epidermis. Development 1992;115:587-93.

[21] McElwee KJ, Kissling S, Wenzel E, Huth A, Hoffmann R. Cultured peribulbar dermal sheath cells can induce hair follicle development and contribute to the dermal sheath and dermal papilla. J Invest Dermatol 2003;121:1267-75.

[22] Osada A, Iwabuchi T, Kishimoto J, Hamazaki TS, Okochi H. Long-term culture of mouse vibrissal dermal papilla cells and de novo hair follicle induction. Tissue Eng 2007;13:975-82.

[23] Ito Y, Hamazaki TS, Ohnuma K, Tamaki K, Asashima M, Okochi H. Isolation of murine hair-inducing cells using the cell surface marker prominin-1/CD133. J Invest Dermatol 2007;127:1052-60.

[24] Kelm JM, Ehler E, Nielsen LK, Schlatter S, Perriard JC, Fussenegger M. Design of artificial myocardial microtissues. Tissue Eng 2004;10:201-14.

[25] Takeda A, Matsuhashi S, Shioya N, Ihara S. Histodifferentiation of hair follicles in grafting of cell aggregates obtained by rotation culture of embryonic rat skin. Scand J Plast Reconstr Surg Hand Surg 1998;32:359-64.

[26] Ihara S, Watanabe M, Nagao E, Shioya N. Formation of hair follicles from a single-cell suspension of embryonic rat skin by a two-step procedure in vitro. Cell Tissue Res 1991:266:65-73.

[27] Lin SJ, Hsiao WC, Jee SH, Yu HS, Tsai TF, Lai JY, et al. Study on the effects of nylon-chitosan-blended membranes on the spheroid-forming activity of human melanocytes. Biomaterials 2006;27:5079-88.

[28] Lin SJ, Jee SH, Hsaio WC, Lee SJ, Young TH. Formation of melanocyte spheroids on the chitosan-coated surface. Biomaterials 2005;26:1413-22.

[29] Lin SJ, Jee SH, Hsiao WC, Yu HS, Tsai TF, Chen JS, et al. Enhanced cell survival of melanocyte spheroids in serum starvation condition. Biomaterials 2006;27: 1462-9.

[30] Young TH, Yao CH, Sun JS, Lai CP, Chen LW. The effect of morphology variety of EVAL membranes on the behavior of myoblasts in vitro. Biomaterials 1998;19: 717-24.

[31] Young TH, Hung $\mathrm{CH}$. Behavior of embryonic rat cerebral cortical stem cells on the PVA and EVAL substrates. Biomaterials 2005;26:4291-9.

[32] Li Y, Li GQ Lin CM, Cai XN. One-step collagenase I treatment: an efficient way for isolation and cultivation of human scalp dermal papilla cells. J Dermatol Sci 2005;37:58-60.

[33] Jahoda CA, Reynolds AJ, Chaponnier C, Forester JC, Gabbiani G. Smooth muscle alpha-actin is a marker for hair follicle dermis in vivo and in vitro. J Cell Sci 1991;99:627-36.

[34] Chiu HC, Chang $\mathrm{CH}$, Chen JS, Jee SH. Human hair follicle dermal papilla cell, dermal sheath cell and interstitial dermal fibroblast characteristics. J Formos Med Assoc 1996;95:667-74.

[35] Muller-Rover S, Peters EJ, Botchkarev VA, Panteleyev A, Paus R. Distinct patterns of NCAM expression are associated with defined stages of murine hair follicle morphogenesis and regression. J Histochem Cytochem 1998;46: 1401-10.

[36] Botchkarev VA, Botchkareva NV, Sharov AA, Funa K, Huber O, Gilchrest BA. Modulation of BMP signaling by noggin is required for induction of the secondary (nontylotrich) hair follicles. J Invest Dermatol 2002;118:3-10.

[37] Burstone MS. Histochemical comparison of naphthol AS-phosphates for the demonstration of phosphatases. J Natl Cancer Inst 1958;20:601-15.

[38] Zheng Y, Du X, Wang W, Boucher M, Parimoo S, Stenn K. Organogenesis from dissociated cells: generation of mature cycling hair follicles from skin-derived cells. J Invest Dermatol 2005;124:867-76.

[39] Lichti U, Weinberg WC, Goodman L, Ledbetter S, Dooley T, Morgan D, et al. In vivo regulation of murine hair growth: insights from grafting defined cell populations onto nude mice. J Invest Dermatol 1993;101(Suppl. 1):124S9S.

[40] Ryan PL, Foty RA, Kohn J, Steinberg MS. Tissue spreading on implantable substrates is a competitive outcome of cell-cell vs. cell-substratum adhesivity. Proc Natl Acad Sci U S A 2001;98:4323-7.

[41] Faucheux N, Tzoneva R, Nagel MD, Groth T. The dependence of fibrillar adhesions in human fibroblasts on substratum chemistry. Biomaterials 2006;27: 234-45.

[42] Allen LT, Tosetto M, Miller IS, O’Connor DP, Penney SC, Lynch I, et al. Surfaceinduced changes in protein adsorption and implications for cellular phenotypic responses to surface interaction. Biomaterials 2006;27:3096-108.

[43] Keselowsky BG, Collard DM, Garcia AJ. Integrin binding specificity regulates biomaterial surface chemistry effects on cell differentiation. Proc Natl Acad Sci U S A 2005;102:5953-7.

[44] Hamano T, Teramoto A, lizuka E, Abe K. Effects of polyelectrolyte complex (PEC) on human periodontal ligament fibroblast (HPLF) function. I. Three-dimensional structure of HPLF cultured on PEC. J Biomed Mater Res 1998;41: 257-69.

[45] Santini MT, Rainaldi G. Three-dimensional spheroid model in tumor biology. Pathobiology 1999;67:148-57.

[46] Dubessy C, Merlin JM, Marchal C, Guillemin F. Spheroids in radiobiology and photodynamic therapy. Crit Rev Oncol Hematol 2000;36:179-92.

[47] Kale S, Biermann S, Edwards C, Tarnowski C, Morris M, Long MW. Three-dimensional cellular development is essential for ex vivo formation of human bone. Nat Biotechnol 2000;18:954-8.

[48] Khalil M, Shariat-Panahi A, Tootle R, Ryder T, McCloskey P, Roberts E, et al. Human hepatocyte cell lines proliferating as cohesive spheroid colonies in 
alginate markedly upregulate both synthetic and detoxificatory liver function. Jepatol 2001;34:68-77.

[49] Koide N, Shinji T, Tanabe T, Asano K, Kawaguchi M, Sakaguchi K, et al. Continued high albumin production by multicellular spheroids of adult rat hepatocytes formed in the presence of liver-derived proteoglycans. Biochem Biophys Res Commun 1989;161:385-91.

[50] Koide N, Sakaguchi K, Koide Y, Asano K, Kawaguchi M, Matsushima H, et al. Formation of multicellular spheroids composed of adult rat hepatocytes in dishes with positively charged surfaces and under other nonadherent environments. Exp Cell Res 1990;186:227-35.

[51] Hasskarl J, Velupillai P, Piboonniyom SO, Grace M, Munger K. Long-term maintenance of human keratinocytes in vitro. J Invest Dermatol 2005;124 $475-8$.

[52] Hasskarl J, Velupillai P, Munger K. Increased in vitro lifespan of primary human keratinocytes correlates with decreased migration. J Invest Dermatol 2006; 126:1179-81. 